2. Saji T, Yanagawa E, Matsuura $H$, Yamamoto $S$, Ishikita $T$, Matsuo $\mathrm{N}$, et al. Increased serum interleukin-6 in cardiac myxoma. Am Heart J 1991;122:570-80.

3. Soeparwata R, Poeml P, Schmid C, Neuhof H, Scheld HH. Interleukin-6 plasma levels and tumor size in cardiac myxoma. J Thorac Cardiovasc Surg 1996;112:1675-7.
4. Laya MB, Mailliard JA, Bewtra C, Levin HS. Malignant fibrous histiocytoma of the heart: a case report and review of the literature. Cancer 1987;59:1026-31.

5. Korbmacher B, Doering C, Schulte HD, Hort W. Malignant fibrous histiocytoma of the heart-case report of a rare left-atrial tumor. Thorac Cardiovasc Surg 1992;40:303-7.

\title{
LEFT THORACODORSAL ARTERY AS AN INFLOW GRAFT FOR MINIMALLY INVASIVE DIRECT CORONARY ARTERY BYPASS GRAFTING
}

\author{
Go Watanabe, MD, Takuro Misaki, MD, Keijyu Kotoh, MD, and Katsushi Ueyama, MD, Toyama, Japan
}

The thoracodorsal artery (TDA) is one of the branches of the subscapular artery that is the largest branch of the axillary artery. It arises from the third part of the axillary artery and runs in a downward and medial direction along the anterior border of the subscapularis and under the cover of the latissimus dorsi muscle. In the field of dynamic cardiomyoplasty and plastic surgery, the TDA has been used to supply muscle or musculocutaneous flap. ${ }^{1,2}$ The TDA has an attractive caliber and length as an arterial graft. We report the first case in which an in situ TDA was used as an inflow graft for myocardial revascularization.

The patient was a 68-year-old woman with a history of increasing postinfarction angina and cerebral infarction. Cardiac catheterization revealed $90 \%$ stenoses of the proximal left anterior descending artery (LAD) and of an obtuse marginal branch of circumflex coronary artery (OM). Minimally invasive coronary artery bypass grafting (MIDCAB) through a small thoracotomy via the left internal thoracic artery (LITA) and the right gastroepiploic artery was planned to revascularize the LAD and OM. However, the preoperative angiogram had shown total occlusion of the celiac artery. We decided to avoid grafting the right gastroepiploic artery. We concluded that the left TDA could be used as an inflow graft to bypass the OM. The patient was placed in the right lateral position; the LITA was harvested thoracoscopically as a pedicle with the use of video imaging guidance. An incision of approximately $3 \mathrm{~cm}$ was made over the fourth intercostal space along the

From the Department of Surgery, Toyama Medical and Pharmaceutical University, Toyama, Japan.

Received for publication March 2, 1998; accepted for publication April 13, 1998.

Address for reprints: Go Watanabe, MD, Department of Surgery, Toyama Medical and Pharmaceutical University, Sugitani, Toyama 2630, 930-01, Japan.

J Thorac Cardiovase Surg 1998;116:524-5

Copyright (C) 1998 by Mosby, Inc. $0022-5223 / 98 \$ 5.00+0 \quad \mathbf{1 2 / 5 4 / 9 0 8 8 1}$

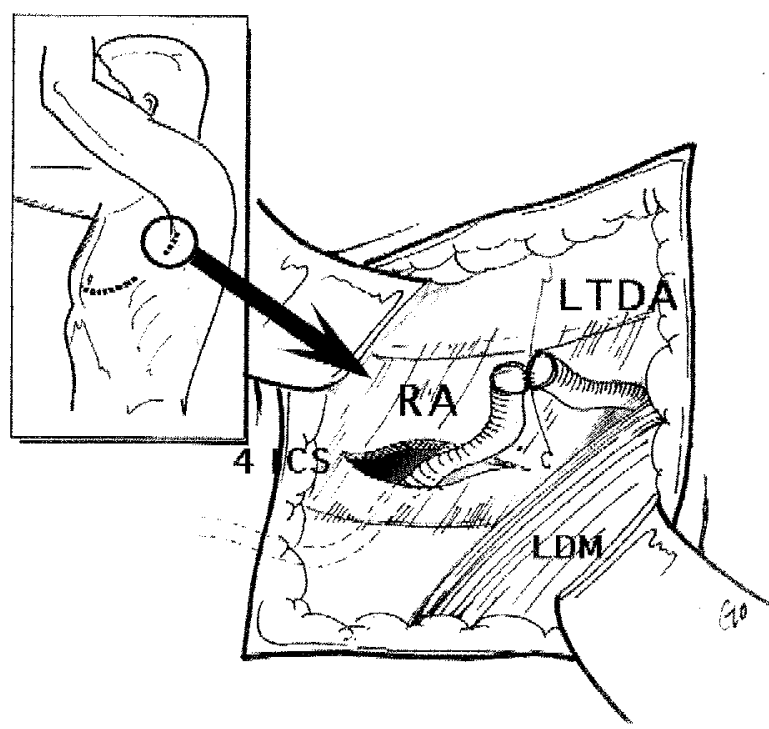

Fig. 1. The minithoracotomy consisted of limited lateral thoracotomy incision in the fifth intercostal space (ICS) and small axillary incision for the left thoracodorsal artery (LTDA) harvesting. LDM, Latissimus dorsi muscle.

anterior margin of the left latissimus dorsi muscle (Fig. 1). The TDA courses between the latissimus dorsi muscle and the serratus anterior muscle and was easily visualized when the latissimus dorsi muscle was retracted laterally. We carefully isolated $8 \mathrm{~cm}$ of the TDA. The diameters of the distal portion of the TDA were $2.5 \mathrm{~mm}$. The size and quality of this artery were similar to those of the LITA in this case. A limited lateral thoracotomy incision was performed in the fifth intercostal spacc; thereafter, the right radial artery (RA) was also harvested. The left TDA was divided distally after heparinization and anastomosed to the free RA with an 8-0 suture. The TDA-RA compositc graft was introduced through the fourth intercostal space via the major fissure of the left lung. Stay sutures 


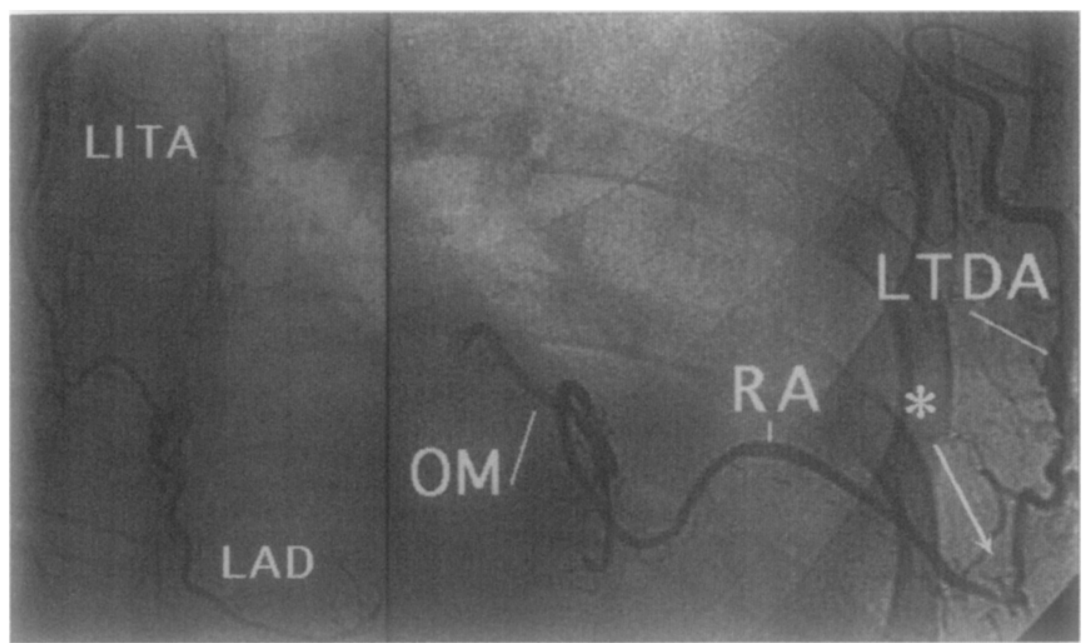

Fig. 2. Postoperative angiogram demonstrates a widely patent RA graft from the in situ left thoracodorsal artery $(T D A)$ to the OM. The asterisk shows the site of the anastomosis.

were applice to the pericardium and pulled upward, thus providing adequate exposure of the coronary arteries. The anastomotic site for the LAD was dissected, and the LAD was occluded proximally with a snaring suture passed around the vessel. The LITA and the left TDA-RA composite graft were anastomosed to the LAD and OM, respectively, without the use of extracorporeal circulation. The use of a coronary stabilizer ${ }^{3}$ to obtain a bloodless field allowed us to perform precise anastomoses. Bleeding was carefully controlled and the thoracotomy was closed. The patient was extubated in the operating room. Neither blood nor inotropic drugs were required. The drainage tube was removed the day after the operation. An angiographic study, performed after the operation with a Judkins-type catheter (4F) via the left radial artery demonstrated that both grafts were patent (Fig. 2). The patient was asymptomatic 4 months after the operation.

Recently, the use of a left minithoracotomy to perform the anastomosis between the LITA and the LAD has been advocated. ${ }^{4,5}$ This standard MIDCAB procedure can be performed on the beating heart with surprisingly little hemodynamic disturbance. However, this procedure does not allow multiple revascularization of coronary arteries because of the inaccessibility of the vessels and the lack of adequate in situ arterial grafts. The MIDCAB procedure with the TDA graft described in this report is suitable for treating patients with isolated left main coronary artery disease or multivessel disease involving the LAD and circumflex systems. To the best of our knowledge, this is the first report of the use of in situ TDA as an inflow graft with the MIDCAB in a patient with multivessel disease. The long-term results with the TDA-RA composite graft and its flow physiologic activity should be studied further. Considering the uncertain nature of these problems, however, we believe the TDA is a suitable inflow graft for a multivessel MIDCAB procedure through a small left thoracotomy.

\section{REFERENCES}

1. Serafin D, Sabatier RE, Morris RL, et al. Reconstruction of the lower extremity with vascularized composite tissue: improved tissue survival and specific indications. Plast Reconstr Surg 1980;66:230-2.

2. Chiu RCJ, Walsh GL, Dewar ML, et al. Implantable extraaortic balloon assist powered by transformed fatigue-resistant muscle. J Thorac Cardiovasc Surg 1987;94:694-701.

3. Takahashi M, Yamamoto S, Tabata S. Immobilized instrument for minimally invasive direct coronary artery bypass: MIDCAB doughnut. J Thorac Cardiovase Surg 1997;114: 680-2.

4. Calafiore AM, Angelini GD. Left anterior small thoracotomy (LAST) for coronary artery revascularization. Lancet 1996; 347:263-4.

5. Subramanian VA, Sani G, Benetti FJ, Calafiore AM. Minimally invasive coronary bypass surgery: a multi-center report of preliminary clinical experience. Circulation 1995;92(Suppl): 1645. 